\title{
Investigation of and Response to 2 Plague Cases, Yosemite National Park, California, USA, 2015
}

\author{
Mary Danforth, Mark Novak, Jeannine Petersen, Paul Mead, Luke Kingry, Matthew Weinburke, \\ Danielle Buttke, Gregory Hacker, James Tucker, Michael Niemela, Bryan Jackson, \\ Kerry Padgett, Kelly Liebman, Duc Vugia, Vicki Kramer
}

\begin{abstract}
$\underset{\text { MDUCAIION }}{\text { Medscape ACTIVITY }}$
This activity has been planned and implemented through the joint providership of Medscape, LLC and Emerging Infectious Diseases. Medscape, LLC is accredited by the American Nurses Credentialing Center (ANCC), the Accreditation Council for Pharmacy Education (ACPE), and the Accreditation Council for Continuing Medical Education (ACCME), to provide continuing education for the healthcare team.

Medscape, LLC designates this Journal-based CME activity for a maximum of 1.00 AMA PRA Category 1 Credit(s) ${ }^{\mathrm{TM}}$. Physicians should claim only the credit commensurate with the extent of their participation in the activity.

All other clinicians completing this activity will be issued a certificate of participation. To participate in this journal CME activity: (1) review the learning objectives and author disclosures; (2) study the education content; (3) take the post-test with a $75 \%$ minimum passing score and complete the evaluation at http://www.medscape.org/journal/eid; and (4) view/print certificate. For CME questions, see page 2241.

\section{Release date: November 16, 2016; Expiration date: November 16, 2017}

Learning Objectives

Upon completion of this activity, participants will be able to:

- Interpret laboratory and epidemiologic findings regarding 2 human cases of plague in 2015 in patients with recent travel history to Yosemite National Park

- Assess environmental findings regarding 2 human cases of plague in 2015 in patients with recent travel history to Yosemite National Park

- Identify critical risk reduction measures used to help prevent plague transmission to Yosemite visitors and staff.

\section{CME Editor}

P. Lynne Stockton Taylor, VMD, MS, ELS(D), Technical Writer/Editor, Emerging Infectious Diseases. Disclosure: $P$. Lynne Stockton Taylor, VMD, MS, ELS(D), has disclosed no relevant financial relationships.

\section{CME Author}

Laurie Barclay, MD, freelance writer and reviewer, Medscape, LLC. Disclosure: Laurie Barclay, MD, has disclosed the following relevant financial relationships: owns stock, stock options, or bonds from Pfizer.

Authors

Disclosures: Mary E. Danforth, PhD; Mark Novak, PhD; Jeannine Petersen, PhD; Paul Mead, PhD, MPH; Luke Kingry, PhD; Matthew Weinburke, MPH; Danielle Buttke, DVM, PhD, MPH; Gregory Hacker, MSc; James R. Tucker, MS; Michael Niemela, MS; Bryan T. Jackson, PhD; Kerry Padgett, PhD; Kelly Liebman, PhD, MPH; Duc Vugia, MD, MPH; and Vicki Kramer, PhD, have disclosed no relevant financial relationships..
\end{abstract}

Author affiliations: California Department of Public Health, Sacramento, California, USA (M. Danforth, M. Novak, G. Hacker,

J. Tucker, M. Niemela, B. Jackson, K. Padgett, K. Liebman,

D. Vugia, V. Kramer); Centers for Disease Control and Prevention,

Fort Collins, Colorado, USA (J. Petersen, P. Mead, L. Kingry);

National Park Service, El Portal, California, and Fort Collins,

Colorado, USA (M. Weinburke, D. Buttke)

DOI: http://dx.doi.org/10.3201/eid2212.160560
In August 2015, plague was diagnosed for 2 persons who had visited Yosemite National Park in California, USA. One case was septicemic and the other bubonic. Subsequent environmental investigation identified probable locations of exposure for each patient and evidence of epizootic plague in other areas of the park. Transmission of Yersinia pestis was detected by testing rodent serum, fleas, and rodent carcasses. The environmental investigation and whole-genome multilocus sequence typing of $Y$. pestis isolates from 
the patients and environmental samples indicated that the patients had been exposed in different locations and that at least 2 distinct strains of $Y$. pestis were circulating among vector-host populations in the area. Public education efforts and insecticide applications in select areas to control rodent fleas probably reduced the risk for plague transmission to park visitors and staff.

$\mathrm{P}$ lague is a zoonotic disease caused by the gram-negative bacterium Yersinia pestis; the organism's reservoir is rodents and the vectors are fleas $(1,2)$. Transmission to humans can occur through bites by infected fleas or through handling $Y$. pestis-infected rodents $(1,2)$. Epidemics of plague still occur on the continents of Africa, Asia, and North and South America (3). Plague was introduced to California in $1900(1,4-6)$, where over the next 25 years it caused occasional outbreaks in rats commensally residing with humans in urban areas $(2,4,6)$. Shortly after its introduction, $Y$. pestis moved into wild rodent populations, establishing a sylvatic transmission cycle $(7,8)$. In subsequent decades, plague spread across California and other western states (9) periodically affecting humans (4-6,10-13).

The human risk of contracting plague is higher during epizootic transmission when $Y$. pestis is amplified among susceptible rodent hosts (2), such as the California ground squirrel (Otospermophilus beecheyi), the golden-mantled ground squirrel (Callospermophilus lateralis), and certain chipmunk species (Tamias spp.) $(2,3,14,15)$. Higher mortality rates among these animals lead to the release of infectious fleas into the environment (2). The California ground squirrel plays a major role in human exposure in California because its predominant flea species, Oropsylla montana, is a competent $Y$. pestis vector $(1,2)$ that is often abundant on this rodent and in its burrows (16) and will readily bite humans $(1,11)$. Since the 1980s, evidence of $Y$. pestis transmission in rodents in the Sierra Nevada mountains has been generally restricted to locations at elevations $>1,200$ meters (California Department of Public Health, unpub. data, 1983-2015). Despite ongoing sylvatic transmission, human plague remains rare in the western United States (17-19), including in California, where no cases have been confirmed since $2006(20,21)$.

During the summer of 2015, the Los Angeles County Department of Public Health (LACDPH) and the Georgia Department of Public Health reported 2 cases of plague in persons who had recently travelled to Yosemite National Park (Yosemite). The California Department of Public Health (CDPH), in collaboration with the US Centers for Disease Control and Prevention (CDC) and the National Park Service (NPS), investigated the increased $Y$. pestis transmission in Yosemite. We summarize the epidemiologic, laboratory, and environmental findings and the public health response.

\section{Methods}

\section{Epidemiologic and Laboratory Investigation}

We defined a case of plague as clinically compatible illness and isolation of $Y$. pestis from a person with a history of travel to Yosemite during the 7 days before illness onset. Clinically compatible illness included fever, headache, chills, and malaise in conjunction with regional lymphadenitis, septicemia, or pneumonia (22). Patients were identified by their county or state health department and reported to $\mathrm{CDPH}$ or $\mathrm{CDC}$.

Diagnosis of plague was made after PCR testing of clinical specimens, including blood and bubo aspirates; Laboratory Response Network assays and culture were used. Recovered isolates were confirmed as $Y$. pestis by bacteriophage lysis (23). For whole-genome multilocus sequence typing (MLST), DNA extracted from $Y$. pestis isolates was sequenced by using the PacBio RS II platform and sequence reads were assembled by using a hierarchal genome assembly process (Pacific Biosciences, Menlo Park, CA, USA). Allele calls for 3,979 Y. pestis open reading frames (ORFs) (4,046,060 bp) and cluster analyses were performed as described (24).

Local and state public health officials interviewed patients with confirmed cases and their family members who had traveled with them. Respondents were asked about their illness history, travel, activities, and interactions with rodents in and around the Yosemite area during the week before illness onset.

\section{Environmental Investigation}

The environmental investigation was prioritized by patient travel itineraries and historical evidence of $Y$. pestis transmission at these locations or in similar habitats. To assess the scope of $Y$. pestis transmission and the potential exposure risk for visitors and park personnel, the investigation was expanded to include additional locations in Yosemite. At prioritized locations, visual risk assessments were conducted to evaluate the presence and abundance of rodents, the type of human activities in the area, and the potential for human exposure to infective fleas (25). In areas with suspected $Y$. pestis transmission, a $30 \times 30 \mathrm{~cm}$ flannel cloth was used to sample fleas from rodent burrow entrances. Rodents were livetrapped for plague serologic testing and flea collection (25). For rodent trapping, Sherman (H.B. Sherman Traps, Tallahassee, FL, USA) and Tomahawk (Tomahawk Live Trap, Hazelhurst, WI, USA) live traps were baited once with a mixture of grains and opened either from overnight through the following midday or from early morning through noon. Relative rodent abundance was estimated by calculating the ratio of captured rodents to the total number of traps set and is referred to as the trap 
success rate. Captured rodents were anesthetized with isoflurane, identified to species, brushed to collect fleas, and subjected to collection of $\approx 0.1 \mathrm{~mL}$ of blood for $Y$. pestis antibody testing. Deer mice (Peromyscus maniculatus) collected near structures were euthanized; all other rodents were marked with a numbered ear tag (National Band \& Tag Company, Newport, KY, USA) and released near the point of capture. Small mammal handling techniques were reviewed and approved by the CDPH Institutional Animal Care and Use Committee, protocol 2015-14. In addition to live rodent trapping, rodent carcasses reported by Yosemite staff or visitors were collected for testing.

Flea and rodent specimens were tested for $Y$. pestis by $\mathrm{CDPH}, \mathrm{CDC}$, and NPS. Blood samples from trapped rodents were sent to CDPH for concurrent testing by passive hemagglutination and passive hemagglutination inhibition to detect antibodies against $Y$. pestis $\mathrm{F} 1$ antigen (23). All positive passive hemagglutination titers $\geq 1: 32$, the lowest dilution tested, that were negative by passive hemagglutination inhibition were considered positive (23). Fleas collected by burrow swabbing, from live-captured rodents, or from rodent carcasses were sent to $\mathrm{CDPH}$ or CDC to be identified to species according to standard taxonomic keys (26) and to be tested for $Y$. pestis. Fleas of the same species from the same burrow or rodent host were sorted into pools of up to 10 fleas and then homogenized in brain-heart infusion broth by using glass beads and Mixer Mill MM301 (Retsch, Haan, Germany).

Rodent carcasses were tested at $\mathrm{CDPH}, \mathrm{CDC}$, and NPS. Spleen and liver tissues were removed; for direct fluorescent antibody testing, slide touch tissue preparations were incubated with fluorescein isothiocyanate-labeled rabbit anti-F1 antibodies, washed, and then viewed by fluorescence microscopy (23). DNA was extracted from flea homogenates and carcass tissues by using the MagNA Pure Compact Nucleic Acid Isolation Kit (Roche Diagnostics, Basel, Switzerland) and amplified by using TaqMan primers and probe targeting the cafl gene (27). Animal and flea specimens positive by PCR were inoculated onto sheep blood agar plates or onto cefsulodinirgasan-novobiocin agar plates to enable isolation of $Y$. pestis from contaminated environmental samples (23). Isolates were confirmed as $Y$. pestis by bacteriophage lysis and typed by whole-genome MLST (24) with the exception that genome sequencing was performed with the MiSeq platform (Nextera XT library preparation, MiSeq Reagent Kit v2, 300 cycle; Illumina, San Diego, CA, USA). Read corrections and assemblies were generated by using SPAdes $3.6(28)$. All diagnostic tests were performed by using standard negative and positive controls.

\section{Results}

\section{Laboratory and Epidemiologic Findings}

On August 2, 2015, LACDPH presumptively diagnosed septicemic plague for a 14-year-old male resident of Los Angeles County (patient 1) and reported the suspected case to CDPH and CDC (L. Tovar Padua, David Geffen UCLA School of Medicine, pers. comm., 2016 Jan 7). LACDPH later confirmed the diagnosis. The patient became symptomatic on July 18, after camping at Crane Flat Campground in Yosemite July 12-17 and visiting Yosemite Valley and Rainbow Pool Day Use Area (Stanislaus National

\begin{tabular}{|c|c|c|c|c|c|c|}
\hline Site & Association & Name & Jurisdiction & $\begin{array}{l}\text { Elevation, } \\
\mathrm{m}\end{array}$ & $\begin{array}{l}\text { Assessment } \\
\text { activity }^{*}\end{array}$ & $\begin{array}{l}\text { Y. pestis } \\
\text { detection }\end{array}$ \\
\hline 1 & Patient 1 visited & Rainbow Pool Day Use Area & Stanislaus National Forest & 850 & $\mathrm{~V}, \mathrm{~B}$ & None \\
\hline 2 & Patient 1 visited & Crane Flat CG & Yosemite National Park & 1,890 & $\mathrm{~V}, \mathrm{~B}, \mathrm{~T}, \mathrm{C}$ & $\begin{array}{l}\text { Serology }+ \text {, } \\
\text { flea pool }+\end{array}$ \\
\hline 3 & Patients 1 and 2 visited & Yosemite Valley & Yosemite National Park & 1,220 & $\mathrm{H}, \mathrm{V}, \mathrm{T}, \mathrm{C}$ & None \\
\hline 4 & Patient 2 visited & Glacier Point & Yosemite National Park & 2,190 & $\mathrm{~V}, \mathrm{~B}, \mathrm{~T}$ & Serology + \\
\hline 5 & Patient 2 visited & Sentinel Dome & Yosemite National Park & 2,470 & $\mathrm{~V}, \mathrm{~B}$ & None \\
\hline 6 & Patient 2 visited & Vernal Falls & Yosemite National Park & 1,510 & $\mathrm{~V}, \mathrm{~B}$ & None \\
\hline 7 & Patient 2 visited & Bass Lake & Sierra National Forest & 1,040 & $\mathrm{H}$ & None \\
\hline 8 & Patient 2 visited & Lewis Creek & Sierra National Forest & 1,280 & $\mathrm{~V}, \mathrm{~B}$ & None \\
\hline 9 & Patient 2 visited & Nelder Grove & Sierra National Forest & 1,640 & $\mathrm{~V}, \mathrm{~B}$ & None \\
\hline 10 & Expanded investigation & White Wolf CG & Yosemite National Park & 2,400 & V & None \\
\hline 11 & Expanded investigation & Porcupine Flat CG & Yosemite National Park & 2,480 & V & None \\
\hline 12 & Expanded investigation & Tamarack Flat CG & Yosemite National Park & 1,940 & $\mathrm{~V}, \mathrm{~B}, \mathrm{~T}$ & Serology + \\
\hline 13 & Expanded investigation & Hodgdon Meadows CG & Yosemite National Park & 1,450 & V & None \\
\hline 14 & Expanded investigation & Tuolumne Meadows & Yosemite National Park & 2,620 & $\mathrm{~V}, \mathrm{~B}, \mathrm{~T}, \mathrm{C}$ & $\begin{array}{c}\text { Serology }+ \text {, } \\
\text { flea pool }+ \\
\text { carcass }+\end{array}$ \\
\hline 15 & Expanded investigation & $\begin{array}{c}\text { Crane Flat-NatureBridge } \\
\text { Campus }\end{array}$ & Yosemite National Park & 1,890 & V & None \\
\hline 16 & Expande & Wawona & Yosemit & 1,220 & C & None \\
\hline 17 & Expanded investigation & Bridalveil Creek CG & Yosemite National Park & 2,130 & V & None \\
\hline
\end{tabular}

${ }^{*} \mathrm{~B}$, burrow swabbing; $\mathrm{C}$, carcass collection; $\mathrm{CG}$, campground; $\mathrm{H}$, historical review; $\mathrm{T}$, rodent trapping; $\mathrm{V}$, visual assessment; +, positive for $Y$. pestis. 


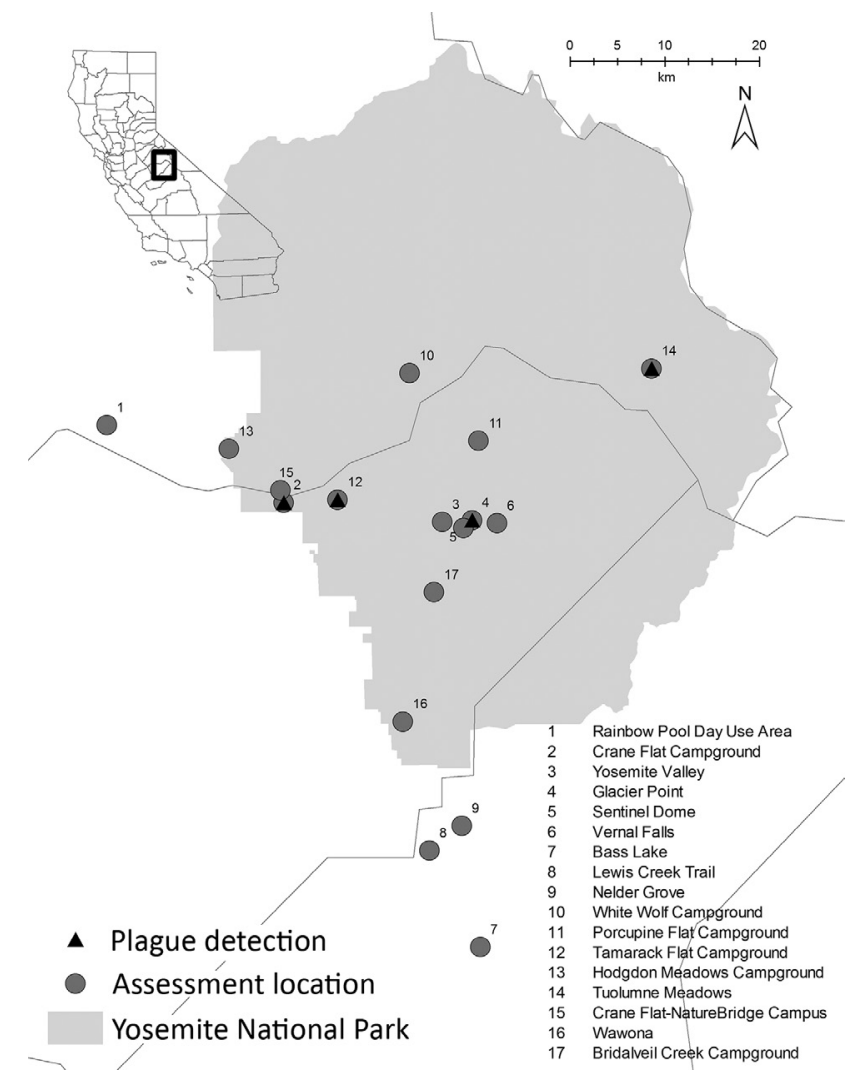

Figure 1. Locations of plague transmission risk assessments in and around Yosemite National Park, California, USA, AugustOctober 2015.

Forest) during this period (Table 1; Figure 1). He reported that he fed squirrels but did not touch them (L. Tovar Padua, pers. comm., 2016 Jan 7).

On August 14, the Georgia Department of Public Health presumptively diagnosed bubonic plague for an 18-year-old female resident of Georgia (patient 2) after she had become symptomatic on August 11. On the same day, CDC was notified of the suspected case and later confirmed the diagnosis. During the prior week, this patient had stayed in a rental home in Oakhurst, California, and visited Yosemite Valley, Vernal Falls, Glacier Point, and Sentinel Dome in Yosemite, as well as NelderGrove, Lewis Creek, andBass LakeintheadjacentSierra National Forest (Table 1; Figure 1). Patient 2 reported having observed numerous squirrels in her vicinity at Vernal Falls and Glacier Point but did not report having had any contact with them.

Neither patient reported seeing dead rodents. Wholegenome MLST showed that the genome sequence of $Y$. pestis isolates from each patient (blood culture from patient 1 , bubo aspirate from patient 2) differed at 21 ORFs (Table 2; Figure 2), including 18 single-nucleotide polymorphisms (SNPs). Each patient was accompanied on the trip by family members who did not become ill.

\section{Environmental Findings}

Plague risk assessments were conducted for 9 locations in Yosemite and the surrounding national forests visited by the patients (Table 1; Figure 1). Within the park, 8 more sites were also evaluated for $Y$. pestis transmission and potential risk areas for transmission to humans.

\section{Sites Visited by Patient 1}

On August 4, the Rainbow Pool Day Use Area (Table 1; Figure 1) was evaluated and deemed to be an area of low risk because of the lack of historical documentation of plague at this habitat and elevation, low abundance of California ground squirrels observed in the day use area, and lack of other diurnal rodent species that are known $Y$. pestis reservoirs in this region. Limited burrow swabbing collected no fleas. A visual evaluation of Yosemite Valley (Table 1; Figure 1) was postponed because it similarly lacked historical documentation of local Y. pestis transmission and because no reports of sick or dying rodents from this heavily visited area had been received. The next week, numerous healthy California ground squirrels were noted in Yosemite Valley. At Crane Flat Campground (Table 1; Figure 1), visual assessment and subsequent burrow swabbing suggested recent epizootic activity; California ground squirrel abundance seemed to be very low relative to the number of burrows in the campground, abandoned burrows were noted, and $134 Y$. pestis-negative fleas were collected from the entrances of 29 (31.5\%) of 94 burrows sampled. Carrion flies (Calliphora latifrons) were also collected or observed at several burrows. Few chipmunks were observed in the campground, but several Douglas squirrels (Tamiasciurus douglasii) were noted. Rodent trapping conducted the following day corroborated the low abundance of rodents (trap success rate 6.9\%; Table 3). Y. pestis antibodies were detected in $1(12.5 \%)$ of 8 California ground squirrels (Table 4), and a pool of 8 O. montana fleas collected from a seronegative California ground squirrel tested positive by PCR for Y. pestis (Table 3). Subsequent whole-genome MLST of $Y$. pestis recovered from this flea pool demonstrated $100 \%$ sequence identity across all ORFs when compared with the isolate from patient 1 (Figure 2).

\section{Sites Visited by Patient 2}

The 7 locations visited by patient 2 were evaluated on August 18 and 19 (Table 1; Figure 1). Bass Lake was not visually assessed because of the historic lack of plague activity in this area. Visual assessments and burrow swabbing at Sentinel Dome, Vernal Falls, Nelder Grove, and Lewis Creek found no obvious indications of $Y$. pestis transmission or increased human risk. Initial evaluation at Glacier Point revealed several abandoned California ground squirrel burrows in close proximity to pathways and picnic areas. From the entrances of the 2 burrows swabbed, 21 fleas 
Table 2. MLST alleles in whole-genome sequences of Yersinia pestis isolates recovered from humans, animals, and fleas, Yosemite National Park, California, USA, August $2015^{*} \dagger$

\begin{tabular}{|c|c|c|c|c|}
\hline MLST allele, ORF & $\begin{array}{l}\text { Y. pestis strain CO9 } \\
\text { genome position }\end{array}$ & Mutation type & Group 1 isolates $\S$ & Group 2 isolates \\
\hline YPCD1.31 & 22450 & SNP & $\mathrm{T}$ & $\mathrm{C}$ \\
\hline YPMT1.46 & 48841 & SNP & $\mathrm{T}$ & $\mathrm{C}$ \\
\hline YPO0193 & 211446 & 6-bp VNTR & - & Loss \\
\hline YPO0445 & 467549 & 1-bp INDEL & - & Deletion \\
\hline YPO0776 & Multiple & 9-bp VNTR & Loss & Gain \\
\hline YPO0894 & 980089 & 15-bp VNTR & - & Gain \\
\hline YPO0968 & 1072143 & SNP & $\mathrm{C}$ & $\mathrm{T}$ \\
\hline YPO0976 & 1084232 & SNP & $G$ & $\mathrm{~T}$ \\
\hline YPO1332 & 1498571 & SNP & $\mathrm{T}$ & C \\
\hline YPO1422 & 1617725 & 18-bp VNTR & Loss & - \\
\hline YPO1705 & 1946021 & SNP & C & $\mathrm{T}$ \\
\hline YPO2153 & 2423508 & SNP & C & G \\
\hline YPO2253 & 2531428 & SNP & $\mathrm{T}$ & $A$ \\
\hline YPO2556 & 2871852 & 6-bp VNTR & Gain & - \\
\hline YPO2840 & 3170905 & SNP & $\mathrm{T}$ & A \\
\hline YPO2842 & 3172167 & SNP & $\mathrm{T}$ & G \\
\hline YPO2859 & 3196474 & SNP & $A$ & $\mathrm{~T}$ \\
\hline YPO3032 & 3385894 & SNP & $A$ & G \\
\hline YPO3339 & 3725154 & SNP & $\mathrm{T}$ & C \\
\hline YPO3409 & 3807578 & SNP & $\mathrm{T}$ & C \\
\hline YPO3419 & 3821161 & SNP & $\mathrm{C}$ & $\mathrm{T}$ \\
\hline YPO3481 & 3886839 & SNP & $\mathrm{C}$ & $\mathrm{T}$ \\
\hline YPO3490 & 3898668 & SNP & $\mathrm{T}$ & C \\
\hline YPO3828 & 4296699 & 8-bp INDEL & - & Insertion \\
\hline YPO4068 & 4587603 & SNP & G & $\mathrm{T}$ \\
\hline \multicolumn{5}{|c|}{$\begin{array}{l}\text { *INDEL, insertion/deletion; MLST, multilocus sequence typing; ORF, open reading frame; SNP, single-nucleotide polymorphism; VNTR, variable number } \\
\text { of tandem repeats; -, none. } \\
\text { †PacBio (Pacific Biosciences, Menlo Park, CA, USA) sequencing of patient isolates yielded an average read length of } 15,541 \mathrm{bp} \text { with } 83,608 \text { average } \\
\text { filtered subreads and an average quality and coverage of } 84.5 \% \text { and } 202 \times \text {, respectively. Illumina MiSeq sequencing of flea and animal isolates yielded ar } \\
\text { average ContigN50 of } 40,440 \text { for the } 6 \text { assemblies and an average read coverage depth of } 84.35 \times \text {. } \\
\text { †Gain/loss and insertion/deletion are relative to the CO92 reference genome. All identified SNPs, VNTRs, and INDELs demonstrated at least } 10 \times \\
\text { sequence coverage and } 100 \% \text { of the base calls confirming the mutation. } \\
\text { §Group 1; patient 1, flea pool from Crane Flat, animals from Tuolumne Meadows. } \\
\text { ॠGroup 2; patient 2. }\end{array}$} \\
\hline
\end{tabular}

were collected. The rodents observed in the area were habituated to humans, and several were noted coming in close proximity to visitors. On the basis of these assessments, Glacier Point was identified as a potential exposure site for patient 2 . Rodents were subsequently trapped and tested (Table 3); 1 (7.1\%) of 14 California ground squirrels and $2(22.2 \%)$ of 9 lodgepole chipmunks (Tamias speciosus) were seropositive (Table 4). All 118 flea pools obtained from Glacier Point, via burrow swabbing or rodent trapping, were negative for $Y$. pestis by PCR.

\section{Expanded Investigation}

On August 10, NPS was notified that 2 dead rodents were found in the Tuolumne Meadows Campground, $\approx 25 \mathrm{~km}$ from the nearest location visited by the patients (Table 1; Figure 1). During the initial assessment, NPS and CDPH staff observed normal rodent diversity and abundance for this location and no fleas were captured by burrow swabbing. Over the following month, 21 rodent carcasses were collected from the campground and adjacent locations, 17 of which were tested for $Y$. pestis; the remaining 4 were too decomposed for testing. The 2 golden-mantled ground squirrel carcasses collected on August 10 and 8 additional rodent carcasses collected in the campground and surrounding area were positive for $Y$. pestis (Table 4). Flea pools from 2 of the rodent carcasses $(1$ Megarthroglossus divisus flea from a Douglas squirrel, 5 Ceratophyllus ciliatus mononis fleas from a lodgepole chipmunk) were also

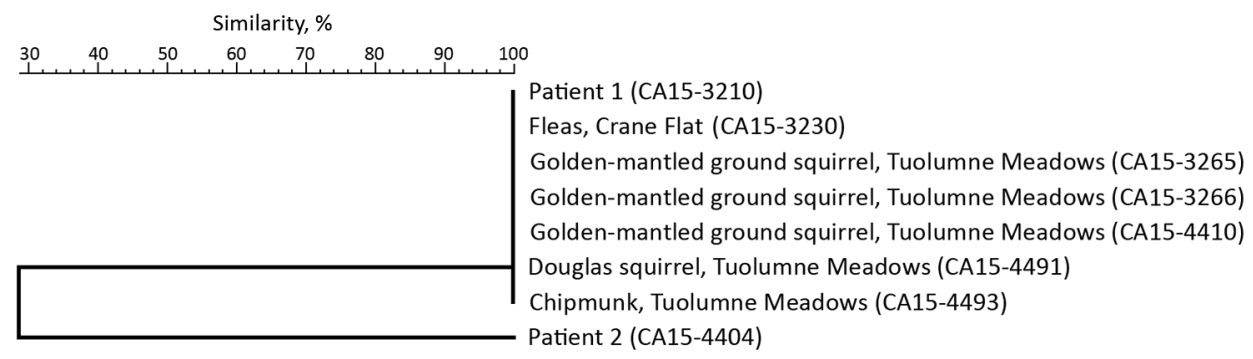

Figure 2. Sequencing results, based on percent similarity, for Yersinia pestis isolates from Yosemite National Park, California, USA, AugustOctober 2015. 
positive by PCR for $Y$. pestis (Table 4). Of the 18 lodgepole chipmunks trapped in this area (Table 3), 3 (16.7\%) were positive for $Y$. pestis antibodies (Table 4). A flea pool (3 Peromyscopsylla hesperomys adelpha fleas) from a seronegative deer mouse also tested positive for $Y$. pestis (Table 4). Whole-genome MLST of 5 Y. pestis isolates recovered from carcasses from Tuolumne Meadows showed that their genome sequences shared $100 \%$ sequence identity across all ORFs, compared with the isolates recovered from patient 1 and the flea pool from Crane Flat Campground (Figure 2).

The expanded environmental investigation found evidence of $Y$. pestis transmission at 1 other location (Table 1; Figure 1). Two visual assessments at Tamarack Flat Campground noted a lower than expected abundance and diversity of rodents and numerous abandoned California ground squirrel burrows. Follow-up trapping (Table 3) led to detection of $Y$. pestis antibodies in $1(20.0 \%)$ of 5 California ground squirrels tested (Table 4). Rodent trapping for testing was also conducted in Yosemite Valley in mid-October. None of 13 California ground squirrels and 15 Peromyscus mice tested positive for $Y$. pestis antibodies (Table 3). Six rodent carcasses from developed sites in Yosemite Valley and 3 from the Wawona area also tested negative for $Y$. pestis.

\section{Flea Control}

Sites with evidence of recent $Y$. pestis transmission and an increased risk for human exposure were temporarily closed, and rodent burrows were treated with insecticide to reduce flea populations and protect wildlife and human health. The following 5 areas in Yosemite were identified for insecticide treatments: Crane Flat Campground, Glacier Point, Tuolumne Meadows Campground, Tamarack Flat Campground, and the Crane Flat-NatureBridge campus. In total, $16.3 \mathrm{~kg}$ of $0.05 \%$ deltamethrin was used per label instructions to treat an estimated 3,700 rodent burrows. Although time and logistical constraints precluded pre- and posttreatment flea evaluations at all locations, evidence from limited sampling suggested that the insecticide applications reduced the local flea populations. Before treatment at Crane Flat Campground, 134 fleas had been collected from 94 burrows and the California ground squirrel flea index (total no. fleas on rodents/total no. rodents) was 17.5. After the insecticide application, 58 treated burrows yielded no fleas and the California ground squirrel flea index was 1.0. After insecticide application at Glacier Point, the California ground squirrel flea index declined from 8.1 to 2.7. No pretreatment rodent trapping was conducted at the Tuolumne Meadows Campground to provide comparative flea indices for rodents, but the posttreatment flea index for ground-dwelling rodents was 0.9 . Before insecticide application at this site, 80 rodent burrows were marked and sampled, yielding a total of 6 fleas; after treatment, no fleas were found at those same burrows.

\section{Public Outreach}

To further reduce the plague risk for Yosemite visitors and staff, NPS and collaborating agencies initiated an aggressive public education campaign. In $2014, \approx 4$ million persons visited Yosemite (29), and, given that plague cases are rare in the United States, it could not be assumed that most visitors were aware of plague risk or prevention measures. The public education campaign included 3 news releases issued August 6-18, media interviews, and website alerts. The park newsletter, The Yosemite Guide, which was given to persons in every entering vehicle, included information about plague. Placards with plague information were posted at park entrances, locations with confirmed $Y$. pestis transmission, all campgrounds, and many day use locations and trailheads. Educational pamphlets were available to visitors at a variety of locations, including affected campgrounds.

\section{Discussion}

In August 2015, these 2 cases of plague were linked to exposure in the internationally popular Yosemite National Park. The initial public health investigation and response with broad media coverage of the first case led to the rapid recognition and appropriate treatment of the second casepatient (30).

The investigation found little overlap in the travel itineraries of the 2 patients, and isolation of distinct strains of

\begin{tabular}{|c|c|c|c|c|c|c|c|}
\hline Date & Location & Traps set, no. & $\begin{array}{c}\text { Rodents } \\
\text { caught, no. }\end{array}$ & $\begin{array}{c}\text { Trap } \\
\text { success, \% }\end{array}$ & $\begin{array}{l}\text { Rodents } \\
\text { tested, no. }\end{array}$ & $\begin{array}{l}\text { Y. pestis-positive } \\
\text { rodents, no. }\end{array}$ & $\begin{array}{c}\text { Y. pestis } \\
\text { seroprevalence, \% }\end{array}$ \\
\hline Aug 5 & Crane Flat CG & 160 & 11 & 6.9 & 11 & 1 & 9.1 \\
\hline Aug 25 & Glacier Point & 100 & 30 & $30.0^{*}$ & 27 & 2 & 7.4 \\
\hline Aug 25 & Crane Flat CG & 100 & 13 & $13.0^{*}$ & 13 & 0 & 0 \\
\hline Aug 25 & Tamarack Flat CG & 60 & 11 & $18.3^{*}$ & 11 & 1 & 9.1 \\
\hline Aug 26 & $\begin{array}{l}\text { Tuolumne } \\
\text { Meadows }\end{array}$ & 208 & 70 & $33.7^{*}$ & 68 & 3 & 4.4 \\
\hline Sep 24 & Glacier Point & 108 & 33 & 30.6 & 6 & 1 & 16.7 \\
\hline Oct 22 & Yosemite Valley & 175 & 34 & 19.4 & 28 & 0 & 0 \\
\hline Total & All & 911 & 202 & 22.2 & 164 & 8 & 4.9 \\
\hline
\end{tabular}

*Trapping event included overnight hours, which extended the trapping period an additional 12-14 h. CG, campground. 
Table 4. Summary of Yersinia pestis-positive samples, Yosemite National Park, August 5-October 22, 2015*

\begin{tabular}{|c|c|c|c|}
\hline Location and date & Species & Sample type (titer or test) & $\begin{array}{c}\text { Sequence } \\
\text { identification no. }\end{array}$ \\
\hline \multicolumn{4}{|l|}{ Crane Flat CG } \\
\hline Aug 5 & California ground squirrel & Serum (titer 1:64) & NA \\
\hline Aug 5 & California ground squirrel & Flea pool (DFA, PCR, wgMSLT) & CA15-3230 \\
\hline \multicolumn{4}{|l|}{ Tuolumne Meadows } \\
\hline Aug 10 & Golden-mantled ground squirrel & Carcass (DFA, PCR, wgMSLT) & CA15-3265 \\
\hline Aug 10 & Golden-mantled ground squirrel & Carcass (DFA, PCR, wgMSLT) & CA15-3266 \\
\hline Aug 11 & Chipmunk (species unknown) & Carcass (PCR ) & NA \\
\hline Aug 17 & Lodgepole chipmunk & Carcass (DFA, PCR, culture) & NA \\
\hline Aug 26 & Douglas squirrel & Carcass (DFA, PCR, wgMSLT); flea pool (PCR ) & CA15-4491 \\
\hline Aug 26 & Lodgepole chipmunk & Carcass (DFA, PCR, wgMLST); flea pool (PCR) & CA15-4493 \\
\hline Aug 26 & Lodgepole chipmunk & Serum $(1: 1,024)$ & NA \\
\hline Aug 26 & Lodgepole chipmunk & Serum $(1: 512)$ & NA \\
\hline Aug 26 & Lodgepole chipmunk & Serum $(1: 128)$ & NA \\
\hline Aug 25 & California ground squirrel & Serum (1:64) & NA \\
\hline Aug 25 & Lodgepole chipmunk & Serum $(1: 128)$ & NA \\
\hline Sep 24 & Lodgepole chipmunk & Serum $(1: 4,096)$ & NA \\
\hline \multicolumn{4}{|l|}{ Tamarack Flat CG } \\
\hline Aug 25 & California ground squirrel & Serum $(1: 128)$ & NA \\
\hline
\end{tabular}

$Y$. pestis suggested that at least $2 Y$. pestis strains were circulating among vector-host populations in the Yosemite area. In the only area visited by both patients, Yosemite Valley, no evidence of $Y$. pestis transmission in rodents was found, and $Y$. pestis has not been detected in the valley's rodent populations in recent decades (CDPH, unpub. data, 1984-2015). We were able to connect the exposure of patient 1 to epizootic transmission at the campground on the basis of the visual observations at Crane Flat Campground, the positive results for rodent serology and the pool of fleas collected there, and whole-genome MLST analysis of $Y$. pestis isolates from patient 1 and the flea pool. The most likely exposure site for patient 2 was Glacier Point, $20 \mathrm{~km}$ away, on the opposite side of Yosemite Valley. Although $Y$. pestis-seropositive rodents were found at this location, we did not detect active infection in rodents or fleas and were therefore unable to directly link the patients' exposure to this site by whole-genome MLST. Previous findings indicate that $Y$. pestis whole-genome MLST alleles are not rapidly changing and that most detected changes are caused by the more slowly evolving SNPs than by more rapidly changing variable number tandem repeats (24). Our results are consistent with those of a previous SNP-based study, which indicated that widespread plague epizootics are caused by multiple $Y$. pestis clones arising independently in small geographic areas (31).

The environmental investigation found evidence of $Y$. pestis transmission in disparate locations of the park, including epizootic activity in the Tuolumne Meadows area, $\approx 41$ and $25 \mathrm{~km}$ from Crane Flat and Glacier Point, respectively. Evidence of $Y$. pestis transmission in rodents was found at 4 of the 5 areas trapped. Of the 8 species of rodents live trapped in Yosemite, $Y$. pestis antibodies were detected in only $5(15.2 \%)$ of 33 lodgepole chipmunks and $3(7.3 \%)$ of 41 California ground squirrels (Table 5). However, $Y$. pestis was also isolated from golden-mantled ground squirrel and Douglas squirrel carcasses and a deer mouse flea, indicating broader zoonotic involvement.

\begin{tabular}{lcc}
\hline Table 5. Summary of Yersinia pestis serology results, by species, Yosemite National Park, August 5-October 22, 2015 \\
\hline Animal (taxonomic name) & Y. pestis-positive & $\begin{array}{c}\text { Y. pestis } \\
\text { rodents, no. }\end{array}$ \\
seroprevalence, \%
\end{tabular}


During the environmental investigation, serum samples collected from 2 bears killed in Yosemite earlier in the summer were positive for $Y$. pestis antibodies. One bear, killed in July on Tioga Road $\approx 18 \mathrm{~km}$ from Crane Flat Campground, was a cub, indicating that exposure was probably recent. Bears serve as sentinels for plague distribution (32), and in recent decades $\approx 10 \%$ of bear blood samples from the Yosemite area have been positive for $Y$. pestis antibodies (CDPH, unpub. data, 1980-2015).

In addition to Yosemite, in 2015, increased $Y$. pestis transmission was evident in other parts of the Sierra Nevada mountains (33). Rodent trapping conducted by CDPH in May and June found elevated $Y$. pestis seroprevalence among rodents in Tulare County. A golden-mantled ground squirrel carcass collected in August from Sequoia-Kings Canyon National Park, also in Tulare County, tested positive. In August, evidence of epizootic activity was also detected in Mono and El Dorado Counties.

The plague activity in Yosemite and other parts of California in 2015 was part of a larger regional trend. Although plague is rare in the United States (median $3 \mathrm{hu}-$ man cases/year during 2001-2012) (17-19), in 2015, the rate increased in western states (16 cases reported to CDC) $(19,34)$. Synchronous increases in $Y$. pestis transmission in the western United States have been documented previously and are potentially driven by large-scale climatic trends (35).

The 2015 findings for Yosemite share some striking similarities with those associated with the only human plague case previously associated with Yosemite (36). In 1959, a teenage boy became ill after camping along Yosemite Creek trail, $\approx 5 \mathrm{~km}$ from Crane Flat Campground. Subsequent investigation by CDPH and CDC found evidence of a recent epizootic plague event that had decimated the rodent populations near the campsite. During this investigation, $Y$. pestis transmission was also documented in Tuolumne Meadows and at Lake Tenaya.

The rapid interagency investigation and public health response to these cases probably reduced the risk for plague among Yosemite visitors and staff. Critical risk-reduction measures included expanding the investigation to recreational sites beyond those visited by the patients and localized insecticide treatments at sites with $Y$. pestis transmission. Increased educational efforts informing the public about how to reduce their exposure to the cause of this potentially fatal disease contributed to the early diagnosis for patient 2 and to increased reports of finding dead rodents in the park, which led to detection of $Y$. pestis transmission at additional locations.

\section{Acknowledgments}

We thank Ben Schwartz, Rachel Civen, Nicole Green, Amanda Kamali, Chelsea Foo, Cherie Drenzek, Amanda Feldpausch,
Wendy Smith, and Laura Edison, who identified and interviewed the patients, assisted in the environmental investigation, and conducted the patient diagnostics. We are deeply grateful to Kenneth Gage, Rebecca Eisen, Karen Boegler, John Montenieri, Don Neubacher, Ron Bourne, Linda Mazzu, Caitlin Lee-Roney, Garrett Dickman, Myron Grissom, and David Wong. We also thank Gil Chavez and James Watt for their support of the investigation and response, and we thank the CDPH Vector Borne Disease Section staff for their assistance with the environmental investigation and rodent serology work, particularly Renjie Hu, Joe Burns, Sarah Billeter, Melissa Yoshimizu, Robert Payne, and Robert Dugger. In addition, we extend our appreciation to all the laboratory staff members who tested samples from patients and the environment, including Marty Schriefer, John Young, Ryan Pappert, Chris Sexton, Brook Yockey, Laurel Respicio-Kingry, Fengfeng Xu, Rose Longoria, Yismashoa Gebremichael, Margot Graves, Vishnu Chaturvedi, and Elizabeth Wheeler. We also thank the CDC Genome Sequencing Laboratory for PacBio sequencing. Last, we thank the Delaware North Corporation for their cooperation and assistance with the investigation.

This study was partially supported by contract funding from the NPS to Public Health Foundation Enterprises.

Dr. Danforth is a biologist with Public Health Foundation Enterprises assigned to CDPH. Her research interests focus on public health and the epidemiology of vectorborne diseases.

\section{References}

1. Pollitzer R. Plague. Geneva: World Health Organization. 1954

2. Perry RD, Fetherston JD. Yersinia pestis - etiologic agent of plague. Clin Microbiol Rev. 1997;10:35-66.

3. Gage KL, Kosoy MY. Natural history of plague: perspectives from more than a century of research. Annu Rev Entomol. 2005;50:50528. http://dx.doi.org/10.1146/annurev.ento.50.071803.130337

4. Link VB. A history of plague in United States of America. Public Health Monogr. 1955;26:1-120.

5. Caten JL, Kartman L. Human plague in the United States, 1900-1966. JAMA. 1968;205:333-6. http://dx.doi.org/10.1001/ jama.1968.03140320027008

6. Kugeler KJ, Staples JE, Hinckley AF, Gage KL, Mead PS. Epidemiology of human plague in the United States, 1900-2012. Emerg Infect Dis. 2015;21:16-22. http://dx.doi.org/10.3201/ eid2101.140564

7. Barnes A. Surveillance and control of bubonic plague in the United States. Symposium of the Zoological Society of London. 1982;50:237-70.

8. Inglesby TV, Dennis DT, Henderson DA, Bartlett JG, Ascher MS, Eitzen E, et al. Plague as a biological weapon: medical and public health management. Working Group on Civilian Biodefense. JAMA. 2000;283:2281-90. http://dx.doi.org/10.1001/ jama.283.17.2281

9. Antolin JF, Gober P, Luce B, Biggins DE, van Pelt WE, Seery DB, et al. The influence of sylvatic plague on North American wildlife at the landscape level, with special emphasis on black-footed ferret and prairie dog conservation. In: Transactions of the 67 th North American Wildlife and Natural Resources Conference; 2002 Apr 3-7. Washington (DC): Wildlife Management Institute; 2002. 
10. Centers for Disease Control and Prevention. Human plague - four states, 2006. MMWR Morb Mortal Wkly Rep. 2006;55:940-3.

11. Craven RB, Maupin GO, Beard ML, Quan TJ, Barnes AM. Reported cases of human plague infections in the United States, 1970-1991. J Med Entomol. 1993;30:758-61. http://dx.doi.org/10.1093/jmedent/30.4.758

12. Wong D, Wild MA, Walburger MA, Higgins CL, Callahan M, Czarnecki LA, et al. Primary pneumonic plague contracted from a mountain lion carcass. Clin Infect Dis. 2009;49:e33-8. http://dx.doi.org/10.1086/600818

13. Lowell JL, Wagner DM, Atshabar B, Antolin MF, Vogler AJ, Keim P, et al. Identifying sources of human exposure to plague. J Clin Microbiol. 2005;43:650-6. http://dx.doi.org/10.1128/ JCM.43.2.650-656.2005

14. Smith CR, Tucker JR, Wilson BA, Clover JR. Plague studies in California: a review of long-term disease activity, flea-host relationships and plague ecology in the coniferous forests of the Southern Cascades and northern Sierra Nevada mountains. J Vector Ecol. 2010;35:1-12. http://dx.doi.org/10.1111/j.19487134.2010.00051.x

15. Wherry WB. Plague among the ground squirrels of California. J Infect Dis. 1908;5:485-506. http://dx.doi.org/10.1093/ infdis/5.5.485

16. Lang JD. Factors affecting the seasonal abundance of ground squirrel and wood rat fleas (Siphonaptera) in San Diego County, California. J Med Entomol. 1996;33:790-804. http://dx.doi.org/10.1093/jmedent/33.5.790

17. Centers for Disease Control and Prevention. Imported plagueNew York City, 2002. MMWR Morb Mortal Wkly Rep. 2003;52:725-8.

18. Eisen RJ, Enscore RE, Biggerstaff BJ, Reynolds PJ, Ettestad P, Brown T, et al. Human plague in the southwestern United States, 1957-2004: spatial models of elevated risk of human exposure to Yersinia pestis. J Med Entomol. 2007;44:530-7. http://dx.doi.org/10.1603/0022-2585(2007)44[530:HPITSU]2.0.CO;2

19. Kwit N, Nelson C, Kugeler K, Petersen J, Plante L, Yaglom H, et al. Human plague-United States, 2015. MMWR Morb Mortal Wkly Rep. 2015;64:918-9. http://dx.doi.org/10.15585/ mmwr.mm6433a6

20. California Department of Public Health. Yearly summaries of selected general communicable diseases in California, 2001-2010. Sacramento (CA): The Department; 2015.

21. California Department of Public Health. Yearly summaries of selected general communicable diseases in California, 2011-2014. Sacramento (CA): The Department; 2015.

22. Centers for Disease Control and Prevention. Nationally notifiable diseases surveillance system: plague (Yersinia pestis) 1996 case definition [cited 2015 Dec 9]. http://www.cdc.gov/nndss/conditions/ plague/case-definition/1996

23. Chu MC. Laboratory manual of plague diagnostic tests. Washington (DC): US Department of Health and Human Services; 2000.

24. Kingry LC, Rowe LA, Respicio-Kingry LB, Beard CB Schriefer ME, Petersen JM. Whole genome multilocus sequence typing as an epidemiologic tool for Yersinia pestis. Diagn
Microbiol Infect Dis. 2016;84:275-80. http://dx.doi.org/10.1016/j. diagmicrobio.2015.12.003

25. California Department of Public Health. California compendium of plague control; plague surveillance risk evaluation form. Sacramento (CA): The Department; 2015.

26. Hubbard CA. Fleas of western North America: their relation to the public health. Ames (IA): Iowa State College Press; 1947.

27. Liu J, Ochieng C, Wiersma S, Ströher U, Towner JS, Whitmer S, et al. Development of a TaqMan array card for acute febrile illness outbreak investigation and surveillance of emerging pathogens including Ebola virus. J Clin Microbiol. 2016;54:49-58. http://dx.doi.org/10.1128/JCM.02257-15

28. Bankevich A, Nurk S, Antipov D, Gurevich AA, Dvorkin M, Kulikov AS, et al. SPAdes: a new genome assembly algorithm and its applications to single-cell sequencing. J Comput Biol. 2012;19:455-77. http://dx.doi.org/10.1089/cmb.2012.0021

29. National Park Service. Yosemite National Park. Park statistics [cited 2015 Dec 9]. http://www.nps.gov/yose/learn/nature/parkstatistics.htm

30. Rosales R. Second human case of bubonic plague inside Yosemite National Park. Fox26 KMPH News. August 18, 2015 [cited 2015 Dec 9]. http://kmph-kfre.com/archive/second-human-case-ofbubonic-plaque-inside-yosemite-national-park

31. Lowell JL, Antolin MF, Andersen GL, Hu P, Stokowski RP, Gage KL. Single-nucleotide polymorphisms reveal spatial diversity among clones of Yersinia pestis during plague outbreaks in Colorado and the western United States. Vector Borne Zoonotic Dis. 2015;15:291-302. http://dx.doi.org/10.1089/ vbz.2014.1714

32. Clover JR, Hofstra TD, Kuluris BG, Schroeder MT, Nelson BC, Barnes AM, et al. Serologic evidence of Yersinia pestis infection in small mammals and bears from a temperate rainforest of north coastal California. J Wildl Dis. 1989;25:52-60. http://dx.doi.org/10.7589/0090-3558-25.1.52

33. California Department of Public Health. Vector-Borne Disease Section annual report 2015 [cited 2016 Sep 27]. http://www.cdph.ca.gov/ programs/vbds/Documents/VBDSAnnualReport15.pdf

34. Fox M. Oregon girl is the 16th U.S. plague case this year. NBC News. October 30, 2015 [cited 2015 Dec 9]. http://www.nbcnews. $\mathrm{com} /$ health/health-news/oregon-girl-16th-u-s-plague-case-yearn454496

35. Ben Ari T, Gershunov A, Gage KL, Snäll T, Ettestad P, Kausrud KL, et al. Human plague in the USA: the importance of regional and local climate. Biol Lett. 2008;4:737-40. http://dx.doi.org/10.1098/ rsbl.2008.0363

36. Murray KF, Kartman L. Plague in California during 1959. California Vector Views. 1959;6:66-7.

Address for correspondence: Vicki Kramer, Vector-Borne Disease

Section, Infectious Diseases Branch, Division of Communicable Disease Control, California Department of Public Health, 1616 Capitol Ave, MS7307, PO Box 997377, Sacramento, CA 95899, USA; email: vicki.kramer@cdph.ca.gov 